\title{
GUARDAR LA MEMORIA DE LOS MUERTOS
}

\author{
Literatura polaca ante la Shoah
}

\author{
Maciej Zietara \\ Magíster en Filología española \\ Universidad de Varsovia \\ Magíster en estudios latinoamericanos \\ Universidad Nacional Autónoma de México \\ embsub@entelchile.net
}

\begin{abstract}
RESUMEN
Este articulo ofrece una panorámica general de la literatura polaca dedicada al Holocausto, que abarca desde los poemas y diarios escritos durante la II Guerra Mundial por intelectuales judios y polacos, tales como Szlengel y Miłosz.

La autenticidad del relato parece ser un paradigma de la literatura polaca sobre la Shoah: los autores fundamentan sus trabajos sobre su experiencia personal, como sobrevivientes o testigos del Holocausto.

Otro problema enfrentado por la literatura polaca es acerca de la posibilidad de representar la Shoa. Escritas inmediatamente después de la II Guerra Mundial, las narraciones de Borowski tratan el proceso de adaptación de los prisioneros de los campos de concentración al sistema totalitario. Buczkowski rehúsa la tradicional forma novelada y hace de la polifonía de voces una genuina posibilidad de escribir sobre la Shoah. Krall and Grynberg, escritores contemporáneos aún activos basan su trabajo en entrevistas y documentos de sobrevivientes, pero sus decisiones estéticas son totalmente diferentes: según Grynberg, la forma literaria es irrelevante y escribir sobre el Holocausto no debería ser sino el mero registro de los hechos. Hanna Krall crea un sofisticado género narrativo a horcajadas entre la ficción y el reportaje y busca así la forma apropiada para hablar de la Shoah.
\end{abstract}

PaLABRAS Clave: literatura polaca, Shoah, Polonia, judíos polacos.

\section{ABSTRACT}

The article presents a general overview of Polish literature dedicated to the Holocaust, from the poems and diaries written during the II World War by Jewish and Polish intellectuals, such as Szlengel and Milosz. The authenticity of the story seems to be a paradigm of the Polish literature on the Shoah: the authors base their works on their personal experience, as survivors or witnesses of the Holocaust. The other problem undertaken by Polish literature is the very possibility of representing the Shoah. Written immediately after WWII, Borowski's stories deal with the adaptation process of concentration camp prisoners to the totalitarian system. Buczkowski rejects the traditional novel form and makes the polyphony of voices a genuine possibility of writing about the Shoah. The contemporary and still working writers, Krall and Grynberg, base their work on interviews and documents of survivors, 
but their aesthetic decisions are totally different: according to Grynberg, the literary form is irrelevant and writing about the Holocaust should be the mere register of facts. Hanna Krall creates a sophisticated narrative genre between fiction and reportage and looks for an appropriate form to talk about the Shoah.

Key Words: Polish literature, Shoah, Polonia, Polish Jews.

En 1939, la comunidad judía en Polonia contaba con alrededor de tres millones y medio de personas, constituyendo un $10 \%$ de la sociedad polaca. La cultura polaca del período de entreguerras era inconcebible sin la presencia de los judíos polacos.. El narrador polaco más original de la época era probablemente Bruno Schulz, cuya escritura suele ser comparada con la de Franz Kafka. En poesía, destacaban creadores de vanguardia, como Bruno Jasieński, Adam Ważyk, Tadeusz Peiper, y los autores más tradicionales, como Julian Tuwim, Antoni Slonimski y Jan Lechon. Quizás el poeta más renovador en las primeras décadas del siglo XX fue Bolesław Leśmian. Otro judío polaco, Mieczysław Grydzewski, dirigía la revista literaria más importante de la época, "Wiadomości Literackie" ("Noticias literarias"). La mejor literatura infantil era obra de Janusz Korczak y Jan Brzechwa. Al menos la mitad de los miembros de la escuela filosófica de Lwów y Varsovia, como Alfred Tarski y Mojżesz Presburger, eran judíos. Paralelamente, existía un mundo judío no asimilado, ortodoxo, apegado al misticismo jasídico y a las enseñanzas de los tzadiks. Esta realidad quedó borrada con la agresión nazi a Polonia y la puesta en marcha de la "solución final".

La lógica de los agresores respondía al hecho de que las mayores aglomeraciones judías de Europa se encontraran en las zonas polacas ocupadas (como Varsovia, Cracovia o Lódź). En estas ciudades se crearon los mayores guetos, como el gueto de Varsovia, que en 1941 alcanzó la cifra de 450 mil habitantes, adonde fueron también transportados los judios de otras regiones de Europa. En su cercanía se construyeron los campos de exterminio -lejos del centro vital de Alemania, en las zonas donde podían ser destruidos en caso de necesidad. En la Polonia ocupada, las autoridades nazis impusieron la pena de muerte por prestar ayuda a los judíos, una regulación que no existía en los países occidentales, como Francia u Holanda, lo cual limitaba drásticamente las posibilidades de socorrer a los judios en el tiempo de la barbarie. La Shoah se produjo en gran parte en las tierras polacas conquistadas por Hitler, y los intelectuales y artistas polacos se enfrentaron al "hecho más importante de la historia de Europa", en las palabras de Henryk Grynberg.

La Shoah es el tema central de la obra de varios narradores polacos, como Adolf Rudnicki, Hanna Krall, Bogdan Wojdowski y Henryk Grynberg, aparece, sin embargo, como un tema latente en la escritura de prácticamente todos los escritores y poetas polacos de cierta relevancia. Una parte de esta literatura fue creada durante la guerra. En el gueto de Varsovia escribió sus memorias el gran pedagogo y escritor judio-polaco Janusz Korczak; también ahí fueron escritos el "Diario del gueto de Varsovia" de Adam Czerniaków - el Presidente del Judenrat del gueto- y 
la poesia de Władysław Szlengel. En el "lado ario", Zofia Nałkowska escribió sus "Diarios del tiempo de la guerra".

Un ejemplo único de la literatura del gueto de Varsovia es la poesia de Władysław Szlengel. Nacido en 1914, Szlengel era hijo de un pintor judío. Desde 1937 publicó poemas en la prensa literaria de Varsovia y escribia también textos para los populares cabarets musicales de la época. Participó en la defensa de Varsovia de 1939. Desde 1940 estuvo en el gueto. En julio de 1942, al inicio de la "gran acción" del exterminio, Szlengel empezó a escribir poemas-crónicas de la vida y la muerte del gueto. Murió en un búnker durante el Levantamiento de abril de 1943. Para Andrzej Kobos e lwona Opoczyńska, Szlengel era "el más grande y el más trágico poeta judío de la Shoah de lengua polaca". En el poema "Ya es la hora", acusa a Dios de haber abandonado a su pueblo elegido; en "La cuenta" encuentra en el gueto a Dios, "un señor mayor, con una mirada benévola y una larga barba canosa", que, no obstante, "andaba sin la venda" (con la estrella de David) y "dicen que tenía la nacionalidad uruguaya". En "Dos muertes", contrapone irónicamente la muerte "heroica" de los soldados y guerrilleros polacos, "condecorada con una cruz y mencionada en un comunicado" a "la muerte de perro, del basurero" en los guetos y campos de exterminio. Szlengel capta de un modo lúcido la división entre los polacos y los judíos, creada por los muros de los guetos y la perspectiva que tenían muchos habitantes polacos del "lado judío".

En enero de 1943, después del primer ataque de la guerrilla judía contra soldados alemanes, Szlengel escribió el poema "Contraataque", un llamado a una acción militar, que se convirtió en una especie de himno del gueto en lucha. El reproche al Dios judío queda ahí sustituido por un rezo al "Dios alemán":

Escucha, Dios alemán,

como rezan los judios en sus casas "salvajes"

con un garrote o estaca en la mano.

Te pedimos lucha y sangre,

te rogamos por una muerte súbita.

Que nuestros ojos no vean antes

el lento caminar de los rieles.

Dales punteria a muestros ojos, Señor,

para manchar de sangre sus uniformes. (...)

De la calles Niska y Mita. de Muranów

brota el fuego del cañón.

'Es nuestra primavera! !Es el contraataque!

IEs el vino embriagante de la lucha!

Estos son nuestros bosques de guerrilla, 
callejones de Dzika y de Ostrowska.

Tiemblan en los pechos los nimeros del "bloque".

nuestras medallas de la guerra judia.

El grito de las ocho letras brilla en rojo,

como un ariete golpea la palabra REBELION"2.

En 1944, el Comité Judío Nacional publicó en Varsovia, clandestinamente, "Desde el limbo. Poesía", una antología de poemas en torno a la Shoah de los poetas judios y polacos. El libro contiene el poema "Campo di Fiori" del poeta y ensayista Czesław Miłosz (Premio Nobel de Literatura del 1980), escrito durante "la Pascua de 1943", es decir, durante el Levantamiento del Gueto de Varsovia. Miłosz construye el poema a partir del paralelismo entre dos imágenes: la muerte de Giordano Bruno en la hoguera en el Campo dei Fiori de Roma y el gueto en llamas. La plaza de Roma, "salpicada de vino y de trozos de flores", es el escenario de un auto de fe donde muere el filósofo italiano, observado por la "curiosa muchedumbre" que, al apagarse las llamas, vuelve a su cotidianidad, sin la menor reflexión o un gesto de compasión. En la plaza de la muerte otra vez aparecen "cestos de aceitunas y limones". En la otra imagen, una feria está colocada cerca del gueto, la música festiva "acalla las salvas detrás del muro" y la gente en un carrusel, disfruta de "un bello domingo de Varsovia". La vida en el "lado ario" sigue como si no pasara nada, igual que en la Roma del siglo XVI. No se trata, dice Miłosz, de una moraleja sencilla, de que "el pueblo de Varsovia o de Roma / Comercia, disfruta, ama / Sin ver las hogueras de los mártires", sino de la "soledad de los que van a la muerte" y la imposibilidad de expresar esta última experiencia:

"Cuando Giordano Bruno
subia a la hoguera
no habia en el lenguaje humano
ni una sola palabra
para decirle algo
a la humanidad que queda".

Para los destinados a la muerte, para los "olvidados por el mundo" nuestro lenguaje "es ajeno / Como el lenguaje de un planeta antiguo".
" $Y$ todo será una leyenda
y entonces, al cabo de muchos años
en un gran Campo di Fiori
la palabra del poeta incitará a una rebelión".

"Campo di Fiori" es una de las primeras reacciones de la intelectualidad polaca frente a la Shoah. Denuncia la indiferencia de las masas ante la tragedia de los judíos y la gran diferencia entre el "lado ario" y el gueto, aunque los dos pueblos sufrieran la opresión nazi. Es también un

2 Todas las traducciones son del autor del texto. 
reconocimiento de la impotencia, de no poder ayudar a los que mueren en el gueto. El poema plantea dos problemas, a mi juicio, centrales para la literatura polaca sobre la Shoah. El primero es la autenticidad del testimonio. Milosz recuerda con estas palabras el momento de la creación del poema:

"Este poenna, como algunos otros, que venían de una indignación moral, de la ira, fue arrebatado de mí por una coincidencia. Iba a visitar a Jerzy Andrzejewski, que vivia en el barrio Bielany. La línea del tranvía pasaba justo al lado donde estaba el carrusel y se escuchaban los disparos de los guerrilleros. De repente se produjo un embotellamiento y miré por un largo momento lo que estaba pasando. Enseguida escribi el poema. En la casa de Andrzejewski había personas de origen judio que vivian una tragedia personal porque no estaban en el gueto"3.

En las crónicas del gueto y en "Campo di Fiori" de Miłosz, tenemos que ver con la creación del paradigma de la literatura sobre el Holocausto escrita en polaco: es creada por las víctimas y los testigos de la Shoah, o bien se basa en testimonios escritos u orales. No existe un libro de alguna importancia sobre el tema que fuera puramente ficticio, lo cual no es raro encontrar en las literaturas en otros idiomas. La autenticidad del relato que viene del propio autor o de una fuente fidedigna es la condición que ningún autor serio haya transgredido. Por ello, desde esta perspectiva, tienen que parecer ingenuas las obras de los novelistas de otras literaturas que tratan la Shoah como un tema más o, lo cual es más grave, un tema de moda.

Miłosz plantea también otro problema: con qué lenguaje describir el horror. Como observa Michał Głowiński, teórico literario y sobreviviente de la Shoah, "lo que sucedió trasciende nuestra imaginación, trasciende los límites del lenguaje. El Holocausto no era concebible porque se encontraba fuera de las fronteras del lenguaje" relatos sobrios que se limitan a un mero recuento de los hechos, sin construcciones literarias complejas, que pierden cualquier relevancia. El valor documental de la literatura sobre la Shoah llega a ser identificado con el valor artístico.

Justo después del final de la guerra surge el talento narrativo de Tadeusz Borowski, cuya obra se reduce a dos tomos de cuentos, dedicados en su totalidad a la experiencia de los campos de concentración nazis y de la guerra: "Adiós a Maria" (1947) y "El mundo de piedra" (1948)". Borowski fue prisionero de Auschwitz y Dachau entre 1943 y 1945. El protagonista de los "cuentos de lagers" -que tiene el mismo nombre que el autor, Tadek- logró adaptarse a la vida del campo de concentración. Gracias a mejores trabajos encargados por los capos y por los soldados de la "SS", puede sobrevivir en condiciones aceptables, en comparación con otros prisioneros. El objetivo es evitar a toda costa ser "seleccionado" para la muerte, conservarse fuerte y sano. La construcción narrativa -cuentos escritos en primera persona- permiten dar una visión del 
campo de concentración desde adentro. Los personajes de Borowski no son precisamente héroes que se mantienen inquebrantables frente al horror. Borowski da a entender que posturas heroicas eran muy escasas. Retrata a los hombres "lagerados", que asumieron las normas impuestas por el sistema del campo de concentración. La narrativa de Borowski es tanto más reveladora, que se concentra en el proceso de "lagerización", de la adaptación del ser humano a un nuevo sistema de valores, impuesto por el régimen totalitario, sistema que llega a ser concebido como normal detrás de los muros.

Al publicar sus cuentos después de la guerra, el propio Borowski fue acusado, desde la perspectiva católica, de nihilismo ético. En efecto, sus conclusiones están muy lejos de la ética cristiana. El mal no se encuentra fuera del ser humano, no es obra de poderes externos. Borowski comprueba la tesis posterior de Hannah Arendt sobre "la banalidad del mal". Los asesinos de los Einsatzgruppen, los capos de los lagers, en otras circunstancias hubieran sido tal vez ciudadanos ejemplares. Como sostiene el crítico polaco Andrzej Werner, "Borowski expresó un sentimiento fuerte y consciente de culpa y responsabilidad por Auschwitz. Lo prueba tan solo la construcción narrativa de los cuentos. Su narrador, Tadek - Vorarbeiter- es un personaje cercano a Borowski, aunque no idéntico a él. No es un tipo de delincuente del campo, sino un hombre acostumbrado a la existencia en el territorio del lager, que actúa según las reglas no escritas de lo que es digno hacer. Sobra decir que son reglas muy diferentes de las que rigen en el mundo fuera del campo. No obstante, nadie nunca dio un testimonio que ensombreciera la postura de Borowski en el lager". El sentimiento de culpa, tan presente en los sobrevivientes, surge de la pregunta ipor qué sobreviví yo mientras los otros murieron? La lucha por la vida, por un mejor trabajo, una mejor asignación de comida, etc. se producía, al fin y al cabo, a costa de otros prisioneros. Lo expresó un coetáneo de Borowski, el poeta y dramaturgo Tadeusz Różewicz, en un poema de la misma época:

\author{
"Tengo veinticuatro años \\ me salvé \\ camino al matadero. \\ Matan al hombre como se mata al animal \\ lo vi: \\ furgones de gente cortada en pedazos \\ que no alcanzará la salvación \\ Los conceptos son sólo palabras: \\ la virtud y la maldad \\ la verdad y la mentira \\ la belleza y la fealdad \\ el valor y la cobardía.
}




\title{
Igual vale la virtud y la maldad
}

lo vi:

a un hombre que era al mismo tiempo

malo y virituoso.

\author{
Busco al maestro \\ que me devielva la vista, el oido y el habla \\ que nombre nuevamente las cosas y los conceptos \\ que separe la luz de la oscuridad".
}

Como muchos otros intelectuales de la posguerra, Borowski quiso creer que el sistema comunista ofrecería la posibilidad de "separar la luz de la oscuridad", de construir un mundo desde las cenizas, después de la "gran liquidación", para usar las palabras de Czesław Milosz. El escritor se convirtió en un propagandista del régimen y sus cuentos posteriores, sometidos a la estética del realismo socialista, no tienen mayor valor.

El año 1948 significó la plena instauración del totalitarismo soviético en Polonia. El Partido Obrero Unificado Polaco (POUP) se convirtió en el partido único, ejerciendo el poder total que abarcaba todas las dimensiones de la vida. E1 POUP puso fin a un periodo de relativa libertad artística y en 1949 declaró el realismo socialista como la única doctrina de la creación artística. La literatura era considerada por los comunistas como un vehículo especialmente importante de propaganda. El tema judío -como cualquier otro-podía ser presentado únicamente en el esquema maniqueo de la lucha de clases, lo cual convertia el supuesto "realismo" en una caricatura insufrible donde los ricos -tanto polacos, como judios- eran explotadores y colaboracionistas, mientras que los obreros y los campesinos eran solidarios y honestos. El tema de la Shoah perdia de esta manera cualquier sentido. Muchos escritores dejaron de publicar hasta 1956, lo que significó el fin de la era del realismo socialista.

El gobierno comunista, con sus distintas mutaciones, nunca vio con buenos ojos la presencia del Holocausto en el arte o en las investigaciones históricas: al fin y al cabo, la meta de la doctrina soviética era el internacionalismo socialista y la creación del "hombre nuevo" comunista, sin rasgos distintivos de una nación o de un credo religioso. En los años sesenta, el bloque soviético apoyó a los países árabes en el conflicto con Israel, lo cual tuvo una repercusión siniestra en PoIonia: en 1968 la fracción nacionalista del POUP emprendió una campaña antisemita, relegando del partido y de otras instituciones a los polacos de origen judio y obligándoles al exilio. De ahí que los creadores que buscaban más independencia se colocaran necesariamente en la posición de disidencia o, a partir de los años setenta, pasaran a la oposición abierta contra el comunismo.

En 1954 fue publicada una de las obras maestras de la prosa polaca: "El arroyo negro" de Leopold Buczkowski, escrita en 1946. Esta novela experimental, que fue comparada con el "Ulises" de Joyce y con la obra de Faulkner, refleja la Shoah en el antiguo Sureste de Polonia (hoy, Ucrania), donde antes de la guerra convivían las comunidades judía, polaca y ucraniana. La novela es uno de los intentos más logrados de captar la experiencia de la guerra. Buczkowski construye la narración con las voces de los personajes -en su mayoria, miembros de la guerrilla 
judía. La polifonía de las voces, en muchos casos no identificadas, sustituye por completo las formas tradicionales de la narración. Según el crítico polaco Henryk Bereza, Buczkowski "llegó a ser el único épico de la civilización de la guerra, descubriendo, asimismo, la impotencia del arte de la palabra frente al arte del aniquilamiento".

En los años 60 inician su obra los escritores de la generación de los "hijos del Holocausto", que fueron testigos de la Shoah como niños. Uno de ellos es Bogdan Wojdowski, autor de la novela "El pan tirado a los muertos" (1971), sobre el gueto de Varsovia desde su creación en 1940 hasta la "gran acción", los transportes a Treblinka de 1942. El propio Wojdowski, nacido en 1930, fue prisionero del gueto. A la misma generación pertenecen las voces más importantes de la literatura actual sobre la Shoah: Henryk Grynbeg y Hanna Krall. Ambos escritores crearon una obra compleja y siguen escribiendo, dando sus propias respuestas a la pregunta de Miłosz.

Grynberg, poeta, narrador y ensayista, nació en Varsovia en 1936, pero pasó su infancia en el pueblo Dobre, en el ambiente de los judios ortodoxos. Durante la guerra permaneció escondido en el "lado ario". Después de la guerra, estudió periodismo, trabajó en el Teatro Judío de Varsovia. Debutó en 1959 con el cuento "Equipo Antigona". Emigró de Polonia en 1967 y su obra se desarrolló en el exilio en los Estados Unidos. Su narrativa abarca la Shoah y el exilio de los judios en la época comunista, basándose en la experiencia personal o en la historia oral, documentos, memorias escritas. En "Drohobycz, Drohobycz" (1997), Grynberg utiliza las entrevistas con los sobrevivientes de la Shoah; en „Memorbuch" narra la historia de Adam Bromberg, editor polaco de origen judío, quien fue expulsado de la Polonia comunista en 1968. La vida de Bromberg se entrelaza con los relatos de las persecuciones de los judios de las ciudades europeas a partir del Medioevo. En los cuentos y novelas de Grynberg se produce una identificación del autor con sus personajes, que comparten la misma biografia paradigmática, multiplicada en miles de variantes. El propio autor concibe su escritura como el cumplimiento del imperativo de ser "guardián de un gran cementerio", el que salva del olvido a los que perecieron en la Shoah y a los sobrevivientes.

En su obra ensayistica, Grynberg desarrolla la tesis de que la Shoah solo era posible en Europa, hecha con las manos de los europeos, formados por la civilización cristiana. La Shoah surge como la consecuencia de casi dos mil años de educación cristiana, que hizo del judío un ser esencialmente ajeno a la religión y forma de vida cristianas. Grynberg protesta en contra de la "universalización" del Holocausto, del discurso que lo convierte en un "genocidio" abstracto de todas las víctimas del nazismo (polacos, rusos, los alemanes contrarios al nazismo, etc.). Recuerda que la "solución final" tenía por objetivo a los judíos y en los campos de exterminio murieron casi exclusivamente judíos. Los intentos de falsificar el Holocausto, de "camuflarlo" como uno de los "crímenes de guerra", demuestra, según Grynberg, la mala conciencia de los europeos, herederos de la civilización cristiana y cómplices de la Shoah.

Según el autor de "Memorbuch", la literatura sobre la Shoah no debe buscar la forma o satisfacer una ambición artística, sino limitarse al registro de los hechos; pensar en crear una "gran literatura" es totalmente irrelevante. 
Otra perspectiva y otra estética representa la escritura de Hanna Krall. Nacida en 1937 en Varsovia, sobrevivió la Shoah en el "lado ario", escondida por las familias polacas. Trabajó durante muchos años como periodista y corresponsal de prensa. En 1977 publicó "Ganarle a Dios", libro basado en conversaciones con Marek Edelman, el último comandante del Levantamiento del Gueto de Varsovia?. En sus libros posteriores, como "La inquilina" (1985), "Pruebas de la existencia" (1996), "Ahí ya no hay ningún río" (1998), los hechos y los relatos auténticos se cruzan con la ficción, que llena los espacios en blanco de las biografias de los personajes. Uno de los temas centrales de la escritura de Krall es la búsqueda de la identidad, alimentada con la experiencia propia de una niña que tuvo que fingir ser católica para sobrevivir la Shoah. Krall recurre a las técnicas de reportaje, mostrando la textura de sus cuentos, lo cual remarca el juego entre la verdad y la ficción. No rechaza la "bella escritura" y el refinamiento formal. Según su autocomentario, "los judíos desnudos bajaban al foso y yo tenía que encontrar una forma para ello. Las tragedias sin forma son algo impúdico. La forma crea una distancia que permite el mero hecho de contar. Sin una forma, me encontraria en este foso lleno de cadáveres" nótico de sus cuentos y novelas y la refinada forma literaria provocó críticas de que su narrativa está demasiado "bien hecha", llena de trucos literarios que no corresponden a la temática de la Shoah.

Otro miembro de la generación de los "hijos del Holocausto" es Michał Głowiński, autor del libro autobiográfico "Temporadas negras". Głowiński narra la huída del gueto de Varsovia y la vida en los hogares polacos y en un orfanato de monjas, adoptando la perspectiva del niño, sin intentar intelectualizar su experiencia.

La mirada de los escritores que no vivieron la experiencia de la guerra, se vuelve hacia el espacio vacío después de la Shoah. Como en el poema "Ciudad" de Ryszard Krynicki:

\section{"Aprecia buena gestión, limpieza y arden: \\ convirtió la sinagoga en una piscina municipal, \\ en los estacionamientos del mercado \\ no hay ni una huella del cementerio judio".}

El espacio vacio no significa solamente la ausencia de los judíos. Es también, a menudo, la ausencia de las huellas, o de las huellas de las huellas, borradas, por un lado, conforme a la lógica del sistema totalitario que rigió en Polonia hasta 1989 y, por otro, conforme al mecanismo de autodefensa de la memoria que intenta desterrar experiencias traumáticas. Aun cuando constatemos que, muy probablemente, las obras más importantes sobre la Shoah en polaco ya fueron escritas por sus testigos, la literatura polaca sigue enfrentando el reto de guardar la memoria de los muertos, como postula Grynberg. O, en las palabras de Głowiński, aunque estamos lejos de la experiencia directa, podemos todavía "escuchar y anotar la memoria ajena".

3 Edición en castellano: Barcelona, Edhasa, D.L. 1982.

8 Citada por Maria Janion, "Hanna Krall wobec Holocaustu", "Rzeczpospolita", 08.12.2001.

9 Conversación con Michal Glowiński, "Tygodnik Powszechny" 25.03.2001. 


\section{BIBLIOGRAFÍA}

ARENDT, Hannah

Eichmann w.Jerozolimie. Rzecz o banalności zla

Kraków 1987.

BOROWSKI, Tadensz

Nuestro hogar es Auschwitz

(trad. K. Olszewska y S. Trigán)

Alba, Barcelona, 2004.

BLOŃSKI, Jan, Marek EDELMAN, Czesław MLLOSZ i Jerzy TUROWICZ

"Ludzkość która zostaje", "Tygodnik Powszechny", 01.05.2005.

GLOWIŃSKi, Michał

Czarne sezony

Wydawnictwo Literackie, Kraków, 2002.

GRYNBERG, Henryk

Wrócilem. Wiersze z lat 1964-1989

PIW, Warszawa, I991.

GRYNBERG, Henryk

Memorbuch

WAB, Warszawa, 2000.

GRYNBERG, Henryk

Uchodzcy, Swiąt

Książki, Warszawa, 2004.

GRYNBERG, Henryk

Drohobycz, Drohobycz

WAB, Warszawa, 2005.

JANION, Maria

"Hanna Krall wobec Holocaustu. Rzeczpospolita", 08.12.2001

KOBOS, Andrzej

Iwona Opoczyńska

"Władysław Szlengel: kronikarz tonących", "Zwoje" 4 (8), 1998.

KRALL, Hanna

Dowody na istnienie

a5, Poznań, 1995. 
KRALL, Hanna

To ty jesteś Daniel

a5, Kraków, 2001.

RYSZARD Krynicki

Kamień, szron

a5, Kraków 2005.

Conversación con Michał Głowiński, "Tygodnik Powszechny" 25.03.2001.

SZEPS Zew (wybór, przeklad i opracowanie)

Antologia poezji żydowskiej (1868-1968),

Oficyna Poetów i Malarzy, Londyn 1980.

ANDRZEJ Werner,

"Zlo jest poza nami", "Gazeta Wyborcza", 08.09.2007. 